\title{
TWO CASES OF YOUNG FEMALES SUFFERING FROM STROKE WITH PROTEIN S DEFICIENCY
}

\author{
PRATYAY HASAN $^{1}$, SHAMIM CHOWDHURY ${ }^{2}$, AHMEDUL KABIR ${ }^{3}$, SUDIP RANJAN DEB ${ }^{4}$, MAHBUB HOSSAIN $^{5}$, \\ ANWAR HOSSAIN ${ }^{6}$, MAMUNUR RASHID BHUIYAN ${ }^{7}$
}

\begin{abstract}
"Young stroke" or "stroke with undetermined cause" is an interesting phenomenon. Though in the absence of any epidemiological study, or available statistical data, true prevalence or incidence of these types of clinical problems in our country cannot be determined, there is a growing concern among the clinicians about the emergence of such diseases in ourpopulation. There is even less familiarity of us with the protein $S$ and problems arising from its deficiency. Though its role is well established in causing thrombophilia derived venous thrombosis, in recent days it has been implicated and recognized as an important factor causing arterial thrombosis and diseases like strokes, especially in the young. We present here two cases of young strokes, both females, who got admitted into same Medicine Unit in Dhaka Medical College Hospital within a year and subsequently, after exclusion of every possible typical and atypical causes, were found with Protein S deficiency.
\end{abstract}

Received: 12 March 2014

Accepted: 19 December 2014

\section{Introduction}

The discourse on "young stroke" has gained much interest among the stroke neurologists. Yet more interesting and more encompassing entity may be "stroke with undetermined cause", in which the commonly associated risk factors cannot be identified. Protein $\mathrm{S}$ is a vitamin $\mathrm{K}$ dependent plasma glycoprotein named after the City of Seattle in which it was discovered in 1976 by Di Scipio et. $\mathrm{al}^{1}$. Protein S has been implicated in pathogenesis of young stroke in recent years, in many case studies. There is no epidemiological study of young stroke or Protein S deficiency in our country. But recurrent attack of deep vein thrombosis due to protein S deficiency has been reported in our country before ${ }^{2}$ and in Japanese and Chinese populations ${ }^{3}$. We intend to report two cases, both young females, suffering from stroke, found with Protein S deficiency.

\section{Case Report}

Case 1

A 18 year old normotensive, non-diabetic married girl hailing from Rupganj, Narayanganj, got admitted into Dhaka Medical College Hospital with the complaints of weakness of left side of the body for 12 hours. Prior to the weakness she has history of fall 4 days back followed by deviation of mouth to the right side $\&$ slurring of speech. There was no history of headache, vomiting, blurring of vision, convulsion or Loss of consciousness. Her bowel bladder function were intact. She had been in her usual state of health before this event. She is married for 4 years, Para$1+0$; age of the last child was 1 and half year, on contraceptive pill (OCP) for the last 1 year, her menstrual cycle was regular, flow was average, menstrual period lasted 3-5 days. There was no positive family history for any thrombotic events. She was nonsmoker, nonalcoholic \& no history of taking betel nuts. On examination: facial asymmetry, angle of mouth deviated to right, GCS - 12/15; pulse was 70 beats/min, BP- $110 / 70 \mathrm{~mm} \mathrm{Hg}$, respiratory rate$16 / \mathrm{min}$, temp: $98.4^{\circ} \mathrm{F}$, JVP was not raised. On nervous system examination we found, that higher psychic function was intact, patient was conscious, well alert, GCS $12 / 15$, orientation with time, place $\&$ person was intact, her speech was slurred but memory was intact. There was no sign of meningeal irritation, upper motor neuron type facial palsy was seen; motor

1. Medical Officer, Department of Medicine, Dhaka Medical College Hospital, Dhaka

2. Medical Officer, Department of Medicine, Dhaka Medical College Hospital, Dhaka

3. Associate Professor, Department of Medicine, Dhaka Medical College Hospital, Dhaka

4. Assistant Professor, Department of Medicine, Dhaka Medical College Hospital, Dhaka

5. Medical Officer, Department of Medicine, Dhaka Medical College Hospital, Dhaka

6. Assistant Registrar, Department of Medicine, Dhaka Medical College Hospital, Dhaka

7. Medical Officer, Department of Medicine, Dhaka Medical College Hospital, Dhaka

Address of Correspondence: Dr. Pratyay Hasan, Medical Officer, Department of Medicine, Dhaka Medical College Hospital, Dhaka

Bangladesh J Medicine 2015; 26 : 39-42 
function examination revealed: muscle bulk was normal, muscle tone was normal in right upper \& lower limbs but increased in left upper \& lower limbs, , muscle power was normal in right upper $\&$ lower limbs but 4/5 in left upper \& lower limbs, examination of the reflexes revealed: plantar response was flexor in right side extensor in left side, deep reflexes were normal in right but exaggerated in left upper \& lower limbs; she was on hemiplegic gait; Sensory function was intact; cerebellar sign was - intact. On cardiovascular system examination: pulse was 70 beats/min, regular in rhythm, normal in volume, bilaterally symmetrical, no radio-radial \& radiofemoral delay, all the peripheral pulses were palpable, apex beat- in left 5 th intercostal space in midclavicular line $\&$ of no definite character; there was no palpable thrill, parasternal heave or epigastric pulsation; on auscultation: 1st $\& 2$ nd heart sounds were well audible $\&$ there was no murmur/added sound, there was no carotid bruit. Other systemic examination revealed no abnormality.

Investigation reports revealed: CBC: TC of WBC-7800/ $\mathrm{mm} 3, \mathrm{DC}$ of WBC- N-62.8\%, L-33.3\%, Hb-12.2 g/dL; ESR-28 mm at 1 st hour, platelet count-272000/mm3; LFT, S. electrolyte, renal function test\& sugar profile and lipid profile were within normal limit. X-ray chest P/A view was- unremarkable \& ECG revealed right axis deviation, MRI of brain showed acute infarct in right cerebral hemisphere (temporo-parietal region), Echocardiography was normal, good LV function (EF$68 \%$ ), noregional wall hypokinesia was seen. VDRL test came non- reactive $\&$ Hepatitis $B, C$ profile was negative. Then atypical causes of the stroke were investigated, which included: ANA- negative, Protein C- $169 \%$ (normal range 70-130\%), MR angiogram: negative, Protein S- 5\% (normal range 60->130\%) done 1 month after admission. She was initially treated with aspirin (75mg OD), atorvastatin (10mg OD) \&vinpocetine $(5 \mathrm{mg})$; as patient developed gastrointestinal upset after starting aspirin it was then stopped. Later warfarin (2.5 mg OD) was added $\&$ patient responded well.

\section{Case 2}

A 21 years old normotensive, non-diabeticlady, hailing from Matlab, Chandpur, got admitted into Dhaka Medical College Hospital with the complaints ofright sided weakness $\&$ loss of speech for 2 days following lower segment (uterine) caesarean section operation. She has $\mathrm{H} / \mathrm{O}$ fall before the incident but there was no history of headache,vomiting, blurring of vision, convulsion or loss of consciousness.Her bowel \& bladder function was intact. She was primi-gravida\& her LUCS was done due toprolonged labour (41weeks of pregnancy with unfavorable cervix)\& it was done with subarchnoid blockade. She gave birth to a healthy female baby of $2.7 \mathrm{~kg}$.Her $1 \mathrm{st} \& 2$ nd trimester was uneventful \& she was fully immunized against all EPI diseases. She is married for 3 years, Para- $1+0$; ALC-2 days. Shehad used OCP as contraceptive method during early married life. There was no positive family history. She was non-smoker, nonalcoholic \& has no $\mathrm{H} / \mathrm{O}$ of taking betel nuts. On examination: she was conscious, GCS- E 4+M 5+ V 2+ 12/15; pulse74 beats/min, BP-130/60mm-Hg,respiratoryrate-18/ min,temp: $98.4^{\circ} \mathrm{F}$, JVP- not raised. On nervous system examination: Higher psychic function: patient was conscious, well alert, GCS $13 / 15$, orientation with time, place $\&$ person was not impaired. There was no sign of meningeal irritation, all the cranial nerves were intact, Motor: muscle buck was normal, muscle tone was normal in left upper \& lower limbs but increased in in right upper $\&$ lower limbs, , muscle power was normal in right upper $\&$ lower limbs but1/ 5 in left upper \& lower limbs, Reflexes: plantar response was flexor in left side but extensor in right side, deep reflexes: normal in left side but exaggerated in right upper \& lower limbs; sensory function was intact, cerebellar function wasintact. On cardiovascular system examination: pulse was 74 beats / min, regular in rhythm, normal in volume, bilaterally symmetrical, no radio-radial \& radiofemoral delay, all the peripheral pulses were palpable, apex beat was in left 5 th intercostal space in midclavicular line $\&$ of no definite character; there was no palpable thrill, parasternal heave or epigastric pulsation; on auscultation: 1 st $\& 2$ nd heart sounds were well audible $\&$ there was no murmur/added sound, there was no carotid bruit. Other systemic examination revealed nothing abnormality.

Investigation reports revealed: $\mathrm{CBC}$ : TC of WBC$14500 / \mathrm{mm} 3$, DC of WBC-N-90 \%, L-7\%, Hbg/dL; ESR$28 \mathrm{~mm}$ at 1 st hour,platelet count-272000/mm3; LFT, S. Electrolyte sugar profile, renal function test, lipid profile were within normal limit . X-ray chest P/A view \& ECG were unremarkable, CT scan of brain showed microvascularischemia in left parietal region with cerebral oedema, Echocardiography: normal, good LV function(EF-61\%), no regional wall hypokinesia. VDRLtest came non- reactive\&hepatitis $\mathrm{B}, \mathrm{C}$ profile was negative. Then atypical causes of the stroke were investigated, which included: ANA- negative, Antiphospholipid antibody (IgG\&IgM)- negative, S. Homocysteine level-7.85 $\mu \mathrm{mol} / \mathrm{L}$ (normal range 4.4413.56)- normal; Protein C level was $>150 \%$, Protein S- $<10 \%$ ( normal range $60->130 \%$ ) done on 5 th day of admission. She was initially treated with ceftriaxone, atorvastatin (10mg OD) \&vinpocetine 
(5mg). Later warfarin (2.5 mg OD) is added $\&$ patient responded well.

\section{Discussion:}

There are certain recognized stroke risk factors among which some are fixed like age, gender, heredity, previous vascular event and high fibrinogen level and some are modifiable like high blood pressure, heart disease (atrial fibrillation, heart failure, endocarditis), diabetes mellitus, hyperlipidemia, smoking, excess alcohol consumption, polycythemia, OCP, social deprivation, etc. ${ }^{4}$ As age is among the risk factors, stroke is often thought to be a disease of the elderly, though in actuality it can happen in all ages from perinatal period to very old age. "Young stroke" may be defined as stroke at 44 years or less age ${ }^{5}$ ). Each age group has characteristic causes, in the adolescence and early adult life, the list of causative factors includes ${ }^{6-9}$ :

1. Pregnancy and puerperium

2. Estrogen related stroke

3. Migraine

4. Vascular malformation

5. Premature atherosclerosis

6. Arteritis/vasculitis/SLE

7. Valvular heart disease

8. Sickle cell anaemia

9. Neurosyphilis

10. CADASIL (cerebral autosomal dominant arteriopathy with subcortical infarct and leucoencephalopathy)

11. Mitochondrial cytopathy

12. Inflammatory bowel disease (UC/CD)

13. Some metabolic diseases, like

a. Homocystenemia

b. Fabry's disease

14. Coagulopathies and thrombophilia:

a. Inherited

i. Factor V Leiden mutation

ii. Prothrombin G20210 mutation

iii. Protein $\mathrm{C}$ deficiency

iv. Protein S deficiency

v. Antithrombin III deficiency

vi. Polygenic that interact with environmental and dietary factors

b. Acquired

i. AntiphospholipidAb syndrome

ii. Heparin induced thrombocytopenia

iii. Lipoprotein A

iv. Patent foramen ovale and venous thromboembolism. v. Congestive cardiac failure

vi. Myeloprofilerative disorder

vii. Bachet's disease

viii. Kawasaki disease

ix. Metastatic malignancy

According to Markus and Humbley, screening for lupus anticoagulant, anticardioplipid antibodies, deficiency of protein $\mathrm{C}, \mathrm{S}$, and antithrombin III is justified in unexplained strokes occurring in children and young adults, in families where members have had frequent strokes and pregnant or parturient women and women who are migraineurs or taking birth control pills(10).Haematological factors indeed may play significant role in causation of thrombotic stroke. Deficiency of any one of the Protein C, Protein $\mathrm{S}$ or Antithrombin III may predispose to in-situ thrombosis within either the arterial or venous system and are a cause of otherwise unexplained strokes in young patients(10).Carod-Artal, et. al.(11) found that prothrombotic conditions are more frequent among the young ischaemic stroke patients classified as strokes of undetermined cause(5). Interestingly they did find association of protein $\mathrm{S}$ desiciency with stroke of undetermined cause but they did not find any association between inherited thrombophilic disorders and any of the subtypes of ischaemic strokes among the older patients.

Protein S deficiency itself can be due to(3):

1. inherited (autosomal dominant)

2. Acquired

a. Vitamin $\mathrm{K}$ antagonists

b. OCP

c. Pregnancy

d. Various

i. Liver disease

ii. Nephritic syndrome

iii. DIC

iv. Chronic infection: HIV

OCP causes reversible decrease in total protein $\mathrm{S}$ level, but not free protein S level. OCP is believed to increase the risk of stroke especially in patients with thrombophilia. Pregnancy also causes decreased protein $\mathrm{S}$ level. The risk of both cerebral infarction and haemorrhage is greatly increased mainly in the 6 week period after delivery rather than during pregnancy itself. Fisher (1971) analyzed 12 postpartum, 9 puerperal, 14 contraceptive cases and 9 patients receiving oestrogen therapy, arterial thrombosis was demonstrated in half of the cases ${ }^{12}$.

In both of our cases we ruled out all other possible causative factors. 


\section{Conclusion}

We believe that in both cases inherited Protein S deficiency which had been dormant previously, due to the effect of OCP or pregnancy, got more pronounced and to such a level as to culminate into arterial stroke.

To confirm the inherited nature of the condition, molecular study should be done to detect PROS 1 or PS-á mutation which is the Protein $\mathrm{S}$ encoding gene situated on the chromosome 3 near the centromere at 3q11.2(3) by PCR amplification followed by single strand conformation polymorphism or denaturing gradient gel electrophoresis analysis and DNA sequencing and particularly direct DNA sequencing(13). DNA based assays are not affected by acute thrombotic event or use of anticoagulants or thrombolytic therapy hence can be performed at any time(14)(15). Plasma based assays for these disorders should be repeated 3-6 months after the initial thrombotic episode to avoid false positive results and unnecessary prolonged anticoagulation therapy. The assays should be done at least 2 weeks after discontinuation of oral anticoagulation or heparin(14)(15). Asymptomatic carriers are not recommended for anticoagulation but symptomatic carriers can be treated according to same routine as for venous thromboembolism(7).Though anticoagulation should be avoided in the acute phase, to avoid the risk of haemorrhagic transformation.

\section{References}

1. Di Scipio R, Hermodson M, Yates S, Davie E. A comparison of human prothrombin, factor IX (Christmas factor), factor X (Stuart factor), and protein S. Biochemistry. 1977;(16): p. 698-706.

2. Hossain A, Islam Q, Kulsum U, Banik J, Rahman $\mathrm{H}$, Hasan M. A case of deep vein thrombosis due to protein $\mathrm{C}$, protein $\mathrm{S}$ deficiency and hyperhomocystenemia, a rare genetic abnormalities. Bangladesh Journal of Medicine. 2011; 22(1): p. 27-29.

3. Ten Kate M, Van Der Meer J. Protein S deficiency: a clinical perspective. Haemophilia. 2008;(14): p. 1222-1228.

4. Allen C, Lueck C, Dennis M. Neurological disease. In Colledge $\mathrm{N}$, Walker $\mathrm{B}$, Ralston $\mathrm{S}$, editors. Davidson's principles and practice of medicine.
Edinburgh: Churchill Livingstone Elsevier; 2010. p. 1181.

5. Adams (Jr.) H, Bendixen B, Kappelle L, et. al.. Classification of subtype of acute ischaemic stroke: definitions for use in a multicenter clinical trial. TOAST. Trial of Org 10172 in Acute Stroke Treatment. Stroke. 1993; 24(1): p. 35-41.

6. Ropper A, Samuels M. Cerebrovascular disease. In Adam \& Victor's Principles of Neurology. Boston: The Tata McGraw-Hill, Inc.; 2009. p. 747.

7. Ng K, Loh P, Sharma V. Role of investigating thrombophilic disorders in young stroke. Stroke Research And Treatment. 2011; 2011.

8. Irfan A. Protein S deficinecy: A rare cause of hereditary thrombophilia. Pakistan Journal of Medicine. 2003; 42(1).

9. Allen C, Lueck C, Dennis M. Neurological disease. In Colledge $\mathrm{N}$, Walker $\mathrm{B}$, Ralston $\mathrm{S}$, editors. Davidson's principles and practice of medicine. Edinburgh: Churchill Livingstone Elsevier; 2010. p. 1184 .

10. Ropper A, Samuels M. Cerebrovascular disease. In Adam \& Victor's Principles of Neurology. Boston: The Tata McGraw-Hill, Inc.; 2009. p. 752.

11. Carod-Artal F, Nunes S, Portugal D, Fernandes S, Vargas A. ischaemic stroke subtypes and thrombophilia in young and elderly Brazilian stroke patients admitted to a rehabilitation hospital. Stroke. 2005; 36(9): p. 2012-2014.

12. Ropper A, Samuels M. Cerebrovascular disease. In Adam \& Victor's Principles of Neurology. Boston: The Tata McGraw-Hill, Inc.; 2009. p. 747.

13. Morris J, Singh S, Fisher M. Testing for inherited thrombophilia in arterial stroke: can it cause more harm than good. Stroke. 2010; 41(12): p. 2985-2990.

14. Tripodi A, Mannucci P. Laboratory investigations of thrombophilia. Clinical chemistry. 2001; 47(9): p. 1597-1606.

15. Brenner B, Nowak-Gottl U, Kosch A, MancoJohnson M, Laposata M. Diagnostic studies for thrombophilia in women on hormonal therapy and during pregnancy, and in children. Archives of Pathology and Laboratory Medicine. 2002; 126(11): p. 1296-1303.

16. De Frutos P, Fuentos-Prior P, Hurtado B, Sala N. Molecular basis of Protein S deficiency. Thromb Haemost. 2007;(98): p. 543-56. 